\title{
LOS SISTEMAS NORMATIVOS INDÍGENAS EN EL MARCO DEL PLURALISMO JURÍDICO. UN ANÁLISIS DESDE LOS DERECHOS INDÍGENAS
}

ASIER MARTÍNEZ DE BRINGAS 
SUMARIO

I. LOS SISTEMAS NORMATIVOS INDÍGENAS (SNI) Y EL PLURALISMO JURÍDICO. EXPLORACIONES SOBRE SU NATURALEZA Y SENTIDO. II. LOS SNI Y LA IMPORTANCIA DE LO POLÍTICO EN EL JUEGO DEL PLURALISMO JURÍDICO. III. LA JUSTICIA INDÍGENA EN EL ÁMBITO DE LOS DERECHOS HUMANOS: MARCOS CONSTITUCIONALES Y SISTEMA INTERNACIONAL: a) El vínculo del Derecho indígena con el derecho a la cultura propia; b) El vínculo del Derecho indígena con el derecho a la autonomía; c) La coordinación entre jurisdicciones indígena-estatal; d) Justicia indígena y derechos humanos; e) Derecho indígena y su conexión con tierras, territorios y recursos naturales. IV. ESPECIFICACIONES Y COMPLEMENTOS A LOS SNI. V. CONCLUSIONES. 


\title{
LOS SISTEMAS NORMATIVOS INDÍGENAS EN EL MARCO DEL PLURALISMO JURÍDICO. UN ANÁLISIS DESDE LOS DERECHOS INDÍGENAS
}

\author{
ASIER MARTÍNEZ DE BRINGAS \\ Doctor en Derecho \\ Profesor de Derecho Constitucional \\ Universidad de Deusto \\ asier.martinezb@deusto.es
}

\section{LOS SISTEMAS NORMATIVOS INDÍGENAS EN EL MARCO DEL PLURALISMO JURÍDICO. EXPLORACIONES SOBRE SU NATURALEZA Y SENTIDO}

Cuando hablamos de justicia indígena es necesario establecer un punto de conexión con el Pluralismo Jurídico (PJ), categoría más amplia que, hasta ahora, ha gozado de un contenido incierto e indeterminado, utilizándose para calificar como tales situaciones y contextos que ni eran plurales ni necesariamente jurídicos. Hecha esta matización, hablar de justicia indígena implica referir a una denominación más precisa, más omnicomprensiva, como es el de los Sistemas Normativos Indígenas (SNI a partir de ahora). Estos se conforman y despliegan en conflictiva dialéctica con los Sistemas normativos del Estado.

Por tanto, empezaremos por comprender el PJ como aquel contexto en el que dialectizan y se cruzan dos sistemas jurídicos diferentes y autónomos, pero 
que coexisten en el mismo campo social ${ }^{1}$, cada uno válido por sí mismo en lo que a fundamento, validez y legitimidad hace referencia. Ello implica cuestionar, a priori y por inferencia de este presupuesto, cualquier forma de supremacía en la manera de gestionar las relaciones entre Sistemas Normativos estatales y Sistemas Normativos Indígenas. Todos estos sistemas normativos se regirán y articularán por medio de una serie de principios cohesivos como son: el principio de colaboración; el de complementariedad e interconexión; el de coordinación y el de convergencia. El principio de jerarquía normativa, tan nuclear en contextos de monismo jurídico, estaría incapacitado para entender las dinámicas de convergencia y complementariedad reclamada y exigida entre ordenes jurídicos diferentes ${ }^{2}$, como parece ser la práctica mayoritaria del constitucionalismo latinoamericano (y mundial).

Trascender el principio de jerarquía a la Kelsen implica distinguir radicalmente entre sistemas internamente plurales, aquellos con los se expresa un sistema jurídico para definir su diversidad interna; y pluralismo de sistemas: como sería el caso de los SNI frente al sistema normativo estatal.

Los SNI implican una constelación de normas indígenas codificadas consuetudinariamente en torno a un sistema, trascendiendo, con ello, el estrecho valor de lo jurídico, o de lo que se viene adjetivando como jurídico. Lo normativo hace alusión a un contenido cosmovisional, social, cultural, simbólico y jurídico que desborda el mero ámbito de lo jurídico. En este sentido lo normativo alude a esa categoría difusa, pero rica semánticamente, que viene siendo utilizada por los pueblos indígenas y que se traduce como buen vivir y vida digna. De ahí la estrechez de miras cuando desde otro sistema normativo, como el estatal, se trata de reducir lo normativo a lo jurídico, tal y como esto es comprendido en el marco estatal. Lo normativo indígena trasciende lo jurídico estatal, otorgando y

${ }^{1}$ Lo hago en estricta consonancia con la definición dada por MERRY, S. E., «Pluralismo Jurídico» en MERRY S., GRIFFITHS J., TAMANAHA B.Z., Pluralismo Jurídico, Siglo de Hombre Editores, Colombia, 2007, pp. 89-141.

${ }^{2}$ La pertenencia de una norma a un sistema jurídico no depende de su contenido, ni de su fuente originaria de producción, sino del hecho de haber sido creada por entes y mecanismos competentes, siguiendo un procedimiento fijado en un origen último de sentido y validez, como es la norma fundamental llamada Constitución. En palabras de Kelsen el ordenamiento jurídico tiene: «una estructura jerárquica y sus normas se distribuyen en diversos estratos superpuestos. La unidad del orden reside en el hecho de que la creación - y por consecuencia la validez- de una norma está determinada por otra norma, cuya creación, a su vez, ha sido determinada por una tercera norma. Podemos de este modo remontarnos hasta la norma fundamental de la cual depende la validez del orden jurídico en su conjunto». KELSEN, Teoría pura del Derecho, Ed. Nacional de Buenos Aires, Buenos Aires, 1979, p. 147. 
sugiriendo más pistas para enriquecer, fortalecer o complejificar el diálogo entre sistemas normativos.

El concepto de PJ, como se viene entendiendo en un sentido convencional ${ }^{3}$, no puede encerrar la categoría de SNI; estos transcienden el estrecho marco de la juridicidad adhiriendo muchos más matices a la comprensión del sistema. Los SNI desarrollan una función heurística al traducir al marco normativo estatal los contenidos y el sentido de los SNI. Prolongando el sentido de lo expuesto, los SNI no se levantan en abstracto, no se comprenden de manera aislada, sino concomitantemente asociados al contenido material de muchos derechos colectivos indígenas que funcionan como especificadores determinantes de su contenido, como son la territorialidad, la autonomía y la jurisdicción indígena. Es importante, en este esfuerzo, intentar comprender los SNI de una manera no esencialista ${ }^{4}$, cosa que resulta complicado hasta para los propios pueblos indígenas. Los SNI no son un cuerpo normativo ancestral que hace reposar su pretendida altura moral en su condición pre-estatal. Una consideración tal haría imposible el diálogo y la búsqueda de vías de coordinación y complementariedad.

Desde nuestras pretensiones, los SNI pueden ser considerados desde dos planos. Uno sería el plano de la fundamentación, aquel por el que los SNI se constituyen con anterioridad a la conformación del Estado y sus sistemas normativos: preceden, por tanto, a los procesos de constitución de los Estados-Nación. No queremos decir, con ello, que en el orden de la fundamentación los SNI funden nada, más allá que a sí mismos. Únicamente otorgamos un estatuto específico a los SNI. Otro sería el plano de lo normativo, el lugar real donde acontecen los

3 Sería lo que Griffiths ha venido llamando Pluralismo Jurídico débil, esto es, aquel que se desarrolla sobre derecho trasplantado. Ello implica que los «usos y costumbres», «los derechos consuetudinarios indígenas» se incorporan asimilativamente, a veces incluso integrativamente, depende del registro constitucional, al régimen de Derecho del Estado. La perspectiva que aquí proponemos tampoco se identificaría con lo que el mismo autor denomina PJ fuerte, en el que él mismo se sitúa, junto con Leopold Pospisil, M. G. Smith, Eugen Ehrlich, o Sally Falk Moore entre otros. Aún no compartiendo los fondos de estas perspectivas, constituyen un puente pedagógico importante con el que dialogar en este marco normativo. Cf. GRIFFITHS, J., «What is Legal Pluralism», en Journal of Legal Pluralism, 1, (1986), pp.14-37; MOORE S. F., Law as a Process, Routledge, Boston, 1978; EHRLICH, E. Escritos sobre sociología y jurisprudencia, Marcial Pons, Madrid, 2005. Cf. También TEUBNER, G., «The Two Faces of Janus: Rethinking Legal Pluralism», en Cardozo Law Review, no 13, (1992), pp. 1143-1462; "The King's Many Bodies: The Self-Deconstruction of Law's Hierarchy», Law E Society Review, no 31 (4), (1997), pp. 763-787; TAMANAHA, B. Z., «La insensatez del concepto científico social del pluralismo jurídico» en MERRY S., GRIFFITHS J., TAMANAHA B.Z., Pluralismo Jurídico, Siglo de Hombre Editores, Colombia, 2007, pp. 223-276.

${ }^{4}$ TAMANAHA, B. Z., «A Non-Essentialist Version of Legal Pluralism», Journal of Law and Society, 2000, pp. 296-321. 
conflictos como consecuencia de la interactuación entre los sistemas normativos estatales y los SNI, entendiendo lo normativo como un término más prolífico, complejo y plural que lo jurídico, coimplicando, en ello, a otros derechos colectivos indígenas. Por razones prácticas y pedagógicas hablaremos de PJ como el escenario donde se produce interculturalmente el conflicto-diálogo entre legalidades para consensuar lo jurídico, pero conscientes, siempre, de que los SNI implican bastante más. Este es el ámbito que nos interesa y desde el que se ubica todo el sentido de este ensayo.

\section{LOS SNI Y LA IMPORTANCIA DE LO POLÍTICO EN EL JUEGO DEL PLURALISMO JURÍDICO}

La lógica del PJ nos pone ante la evidencia de cambios estructurales que se vienen produciendo como consecuencia de la globalización de los procesos jurídicos. Uno de esos cambios estructurales es la pérdida de la condición monopólica del Estado en la producción y reproducción de Sistemas Normativos. Los SNI vienen a validar esta afirmación. Hablar de SNI supone ubicar en el centro de la discusión el concepto de lo Político. La posibilidad de diseñar un concepto amplio, poroso y elástico de PJ, o por el contrario, restrictivo y estrictamente vinculado a la producción jurídica de los Estados, depende, en última instancia, de la concepción de lo "político» con la que nos vengamos manejando para alcanzar una definición de contenidos y posibilidades. Esta matización sobre el contenido político es fundamental en el supuesto de los pueblos indígenas y, especialmente, en América Latina.

Hasta ahora el PJ se ha venido definiendo a través de un enfoque en el que la política - en cuanto práctica productora de discursos normativos- quedaba subordinada al Estado por medio y a través de los partidos políticos. El resultado inevitable de esta operación ha sido el monopolio político de la producción jurídica por parte del Estado: el monismo jurídico. Versiones débiles de esta operación han sido expresiones de pluralismo donde la fuente de legitimidad y validez última de la producción normativa residía en sede constitucional. Hablar de SNI implica, o ha implicado, la existencia de un «movimiento indígena» que ha pujado enconadamente por alterar y transformar la relación entre Movimiento (indígena) y Política. La existencia de un posible «movimiento indígena» ha pretendido poner en escena otra lógica de poder y, concomitantemente asociada a la misma, otra manera de entender la producción normativa desde los propios SNI, dando contenido material concreto al PJ. Se ha pretendido, durante mucho tiempo, la sustitución de la política de partidos 
por la política de movimientos (indígenas). Una cuestión diferente es si esto se ha conseguido —quizá una aproximación a ello fue el proceso constituyente boliviano-; si ha periclitado este esfuerzo, o si se puede hablar a día de hoy de alguna suerte de movimiento indígena como tensión transformadora de la política en su esencia. De la posibilidad de dar respuesta a este planteamiento depende la suerte del PJ en general, y de los SNI en específico. Por tanto, sin la existencia de un movimiento indígena que replantee las relaciones entre pueblos y el poder estatal; sin que se reformulen y tensionen dialécticamente las posibilidades de adaptación de la jurisdicción indígena al territorio del Estado y de este último a los SNI, con todo lo que esto supone, es muy difícil sostener una idea de PJ para los pueblos indígenas.

La existencia de un movimiento indígena redefine la lógica de la producción normativa estatal y propone como alternativa la dinámica de los SNI. Con ello, lo que se plantea es una profundización en el principio de igualdad material para los pueblos indígenas, en el marco del Estado. Una posibilidad para la consecución de esa igualdad compleja y diferenciada es confrontarse con sistemas normativos otros, diferentes y complejos. Los SNI no tienen una consideración aislada o autónoma de sí mismos, sino que son más bien la prolongación y el mecanismo de profundización en una estrategia política: la que ha venido proponiendo el movimiento indígena. Como hemos dicho, no está claro si éste -el movimiento- existe como tal ahora mismo en América Latina, con lo que se alteraría, también, la tensión en el reclamo y en los modos de enunciación y de legitimidad de los SNI.

La existencia de un movimiento (indígena) en América Latina ha implicado la irrupción de una manera nueva de entender la esencia de lo político, lo que ha implicado una lógica diferente en la comprensión del tiempo y el espacio. Un tiempo distinto que el de la acción y dinámica procesal estatal. Y un espacio diferente, nuevos lugares de representación para la legitimidad indígena, a través de sus propios principios y autoridades, procedimientos, normas y acuerdos resolutivos netamente indígenas. Espacio y tiempos nuevos, como los dos vectores políticos del movimiento indígena, constituyen el lugar desde donde puede interpretarse la novedad del PJ que los SNI proponen. Un espacio jurisdiccional nuevo no mediado ni matizado por la lógica del derecho estatal. Un espacio de legitimidad que permita entender los sistemas de autoridad, de jurisdicción, de validez, de legitimidad, de prescripción, de otra manera, y, desde ahí, poder entender la novedad de un procedimiento y una jurisdicción indígena, mediada políticamente por otras consideraciones de tiempo y espacio.

Otro cambio importante, estructuralmente concatenado al anterior, tiene que ver con la despolitización del Derecho estatal que se ha venido produciendo como 
consecuencia de la acción y reclamo del movimiento indígena en las últimas décadas en América Latina. La despolitización del derecho estatal implica, en paralelo, una repolitización de los SNI: esto es, la validez y legitimidad de otros órdenes normativos allende del orden estatal. La existencia de otros sistemas normativos distintos que reclaman su validez, lugar y tiempo de enunciación.

Una última transformación importante para las consideraciones de este escrito son las alteraciones que, paralelamente, se han producido en el Derecho estatal en cuanto instrumento y principio privilegiado para la transformación social políticamente legitimada. Es aquí donde se ubica con toda su intensidad la labor de un posible movimiento indígena que ha propuesto y desarrollado otras formas de entender la legitimidad y la legalidad, incluso, la transformación, en la manera de entender la soberanía. A ello han ayudado, sin duda, una serie de factores externos que han sido entendidos y utilizados sincrónicamente por el propio movimiento indígena, unas veces con más consciencia, y otras con menos. Entre estos factores habría que citar la tendencia a la flexibilización y porosidad de las fronteras, junto con la idea de Estados abiertos en el sentido de globalización económica; la privatización y transnacionalización que se ha venido haciendo en la producción jurídica en general; la pérdida de capacidad de los Estados para determinar autónomamente el contenido del Derecho; la procedimentalización del derecho, lo que ha implicado una creciente descentralización en la toma de decisiones jurídicas, una mayor informalidad en los modos de producción jurídica y en la comprensión de las fuentes del derecho, implicando una avenida de oportunidades para renegociar jurisdicción y espacios jurídicos desde la lógica de los SNI; junto con fuertes crisis de legitimidad en la arquitectura de los sistemas jurídicos, entendidos, hasta ahora, exclusivamente, como sistemas piramidales, herederos de una manera kelseniana de entender e interpretar el Derechos.

\section{LA JUSTICIA INDÍGENA EN EL ÁMBITO DE LOS DERECHOS HUMANOS: MARCOS CONSTITUCIONALES Y SISTEMA INTERNACIONAL}

Procederemos escalonadamente, desde lo más abstracto, esto es, la vinculación con lo que consideramos principios esenciales que puedan dar sustento y formato a los SNI, amparándonos, para ello, en la normativa internacional de derechos humanos; hacia lo más concreto, sugerido desde sentencias y comenta-

${ }_{5}^{5}$ ESTÉVEZ ARAUJO, El revés del Derecho. Transformaciones jurídicas en la globalización neoliberal, Universidades Externado de Colombia, Bogotá, 2006. 
rios de operadores jurídicos en el marco de la OEA - Comisión y Corte Interamericanas, fundamentalmente- que permitan dar una fisonomía más tangible y articulada al tema que nos ocupa: la fundamentación de los SNI como un derecho específico de los pueblos indígenas.

El reconocimiento del Derecho y la Justicia indígenas quedan recogidos en los artículos 34 y 35 de la Declaración de Naciones Unidas sobre los derechos de los pueblos indígenas ${ }^{6}$. El germen de dichos artículos se encontraba recogido ya en el primer borrador de Declaración elaborado por la Presidenta del Grupo de Trabajo sobre Poblaciones Indígenas de 1989, teniendo allí una consideración más amplia, pues se hablaba del derecho de estos pueblos a un reconocimiento de sus características propias en el «sistema jurídico y en las instituciones políticas y socioeconómicas» ${ }^{7}$. Por tanto, los artículos de la Declaración no son más que expresión final de un proceso de negociación política, de trasiego y selección jurídica, que dista mucho de la consideración de PJ que previamente hemos afirmado. El contenido final de los artículos $34^{8}$ y $35^{9}$ son una traducción de traducciones de lo que sería el sentido originario de los SNI en la manera de entender y articular estas cuestiones y sus contenidos. De ahí que, frente a los términos defendidos en la primera parte de este trabajo, el texto de la Declaración hable reductivamente de «sistemas jurídicos» indígenas, de «derecho indígena», acotando estrictamente el sentido del PJ propuesto. Sin duda la Declaración fue un proceso conflictivo de negociación política sobre términos y categorías cuyo consenso final, plausible en términos de derechos humanos, expurgo las densas dimensiones con las que necesitan expresarse los SNI. Sin embargo, el valor propedéutico y heurístico de la Declaración para la profundización —a través de un largo sendero político de lucha, articulación e implementación de los derechos allí recogidos y reconocidos- es indiscutible ${ }^{10}$. La importancia jurídica y política de su implementación tiene que ver con la

${ }^{6}$ Nos inspiramos en las sugerentes propuestas realizadas por Luis Rodríguez-Piñeiro, «Justicia y Derecho Indígena», en BERRAONDO M. (ed.), La Declaración sobre los Derechos de los Pueblos Indígenas. Punto y seguido, Alternativa, Barcelona, 2008, pp. 123-138.

7 E/CN.4/Sub.2/1989/33(15 de junio de 1989), art. 21.

8 «Los pueblos indígenas tiene derecho a promover, desarrollar y mantener sus estructuras institucionales y sus propias costumbres, espiritualidad, tradiciones, procedimientos, prácticas y, cuando existan, costumbres o sistemas jurídicos, de conformidad con las normas internacionales de derechos humanos».

9 «Los pueblos indígenas tienen derecho a determinar las responsabilidades de los individuos para con sus comunidades».

${ }^{10}$ Cf. CHARTES C. y STAVENHAGUEN R. (eds.), El Desafío de la Declaración. Historia y futuro de la Declaración de la ONU sobre pueblos indígenas, Iwgia, Copenhague, 2010. 
posibilidad de profundizar en los densos sentidos que los SNI poseen en sus articulaciones originarias.

En los procesos de negociación política de la Declaración, y en sus procesos de implementación posterior, así como en lo que constituyen los laboratorios de experimentación más interesantes en materia de derechos indígenas, como consecuencia de sendos procesos constituyentes - como han sido el caso de Bolivia y Ecuador-, se han podido observar enconadas tendencias a limitar el reconocimiento de la Justicia indígena, reconduciéndola, de manera aditiva, a los postulados y exigencias del derecho estatal. También se han podido testar problemas de fondo y de forma que pueden sugerir criterios para el arraigue y la implementación de los SNI en el marco del Estado. Así, en algunos supuestos se ha querido articular el «derecho indígena» a partir de funciones propias que corresponden al derecho estatal, como es la función de control social. Esta desviación, en ambos márgenes del debate, ha llevado a movilizaciones sospechosas, restricciones y retractaciones en el ámbito de interlocución del Estado. Otras veces se ha querido coronar a los SNI con características propias y típicas del derecho oficial y de sus funciones, como reacción alérgica y comprensible a que el Derecho estatal pueda devorar el sentido último de los SNI si estos no se pertrechaban desde el principio con una cierta pretensión de hegemonía. En otras ocasiones hay que constatar la imposibilidad para fundamentar un concepto transcultural de lo normativo y del Derecho que permita identificar derechos en todos los contextos indígenas. Es decir, la imposibilidad de traducir a códigos normativos las expectativas y exigencias de derechos indígenas en un sentido lato.

Si retornamos al artículo 34 de la Declaración, puede atisbarse con claridad en su redacción normativa la existencia de una dicotomía y fractura fundante. Por un lado habla, de manera separada, como desgajado del sentido de los SNI, de «promover, desarrollar y mantener sus estructuras institucionales y sus propias costumbres, espiritualidad, tradiciones, procedimientos, prácticas»; por otro lado habla, en un sentido dicotómico, de, cuando existan «costumbres o sistemas jurídicos», como si los dos elementos puestos en confrontación paralela no constituyeran parte integrante e inconsútil de los SNI.

Además de estos dos artículos de la Declaración, el Convenio 169 de la OIT hace referencia, en el artículo 8.1, a «costumbres» y «derecho consuetudinario», que deberán ser tomados en consideración por los Estados al aplicar la legislación nacional. En el 8.2 habla de «costumbres e instituciones propias» cuyo límite de articulación serán los derechos fundamentales reconocidos en 
el ámbito nacional y el Derecho Internacional de los derechos humanos ${ }^{11}$. El artículo 9.1 obliga a los Estados a respetar «los métodos a los que los pueblos interesados recurren tradicionalmente para la represión de los delitos cometidos por sus miembros».

En el contexto americano, el proyecto de Declaración Americana sobre los derechos de los pueblos indígenas incluye un amplio reconocimiento del derecho indígena como "parte del orden jurídico y del marco de desenvolvimiento social y económico de los Estados», regulando, a diferencia de la Declaración de la ONU y del Convenio, la incorporación en el derecho estatal de los «sistemas legales y organizativos indígenas» ${ }^{12}$.

La Corte Interamericana de Derechos Humanos (CIDH) en el caso Awas Tingni otorgó un valor más trascendente y amplio al derecho consuetudinario indígena que los meros valores, usos y costumbres. Es el propio derecho indígena, como una totalidad abstracta, el que sustenta otros derechos más específicos, como el derecho de propiedad comunal sobre tierras, territorios y recursos naturales, en ausencia de un título formal en conformidad con el derecho estatal, teniendo el mismo valor que el mismo ${ }^{13}$.

\section{a) El vínculo del Derecho indígena con el derecho a la cultura propia}

Dicho vínculo queda recogido a través de la conexión entre el artículo 34 y el 11 de la Declaración. En este sentido el Derecho indígena se expresa como derecho a "practicar y revitalizar sus tradiciones y costumbres culturales». Es a partir de este vínculo por el que tiene sentido hablar de SNI, como se ha hecho en la primera parte, esto es, entender que el «Derecho indígena» tiene un fundamento más hondo, más dilatado, más denso, que arraiga en procesos culturales y cosmovisionales, trascendiendo, de esta manera, el simple debate sobre la juridicidad y el derecho. Es por ello que el reconocimiento del derecho indígena implica, de manera inherente, todo el aparato institucional y jurisdiccional necesario para su aplicación y concreción. Por tanto, instituciona-

11 A este respecto, la constitución peruana guarda consistencia con el Convenio al establecer que la jurisdicción especial no debe vulnerar los derechos de la persona. Otras constituciones limitan el reconocimiento de la jurisdicción al respeto de la Constitución y las leyes en un sentido abstracto. Venezuela resulta más restrictiva al establecer como umbral de recorte de la jurisdicción indígena un límite tan omnicomprensivo como el orden público.

12 Proyecto de Declaración Americana, Art. XVI.1

13 CORTE IDH. Caso de la Comunidad Mayagna (Sumo) Awas Tingni Vs. Nicaragua. Fondo, Reparaciones y Costas. Sentencia de 31 de agosto de 2001. Serie C No. 79. 
lidad indígena y jurisdicción propia son condiciones de posibilidad, asideros necesarios de este derecho. El artículo 35 también enfatiza en ello al establecer que los pueblos indígenas tienen derecho a determinar las responsabilidades de los individuos para con sus comunidades. Ello presupone la existencia de un conjunto normativo, de prácticas, de procedimientos, de principios, de referencias institucionales, etc., todas con carácter intracomunitario, que son las que darían contenido y fisonomía a los SNI. Como se ve, el fundamento último de esta conexión es la cultura en su sentido colectivo y complejo. Derivar responsabilidades de estos presupuestos supone trascender la mera consideración de prácticas normativas y ubicarse, más bien, en una consideración de SNI. En todo ello hay un tránsito necesario de una cosmovisión liberal, arraigada en consideraciones individuales de vida y convivencia, como la del Estado, a una cosmovisión colectiva, como es la de los pueblos indígenas, cuyo centro de potencialidades son los SNI. En esta conexión con la cultura se establece también una triangularidad entre derechos colectivos indígenas (territorialidad, autonomía), el derecho indígena y los procesos culturales: todo ello dan medida material de los $\mathrm{SNI}^{14}$.

El artículo 34 también establece algunos límites claros como aquellos supuestos en que sistemas, prácticas, procesos, tradiciones, etc., no se encuentren vigentes, por extinción o por una transformación radical de las prácticas culturales y formas de vida, como podrían ser las migraciones urbanas. Entre estos límites estaría también el hecho de que el derecho estatal rija como derecho supletorio, que bien entendido, tiene una función garantista, interpretado siempre desde la necesaria tensión entre derechos individuales y colectivos; más que de simple coerción de la razón jurídica de Estado sobre el derecho indígena. Sin embargo, la regulación y tasación concreta de la supletoriedad, asegurando su valor instrumental más que sustantivo, es importante para que esta cláusula no funcione como criterio sistemático de invasión y subsunción de un sistema normativo por el otro.

De alguna manera el artículo 34 no hace sino apuntalar el carácter dinámico, fluyente y cambiante del derecho indígena, en conexión última con las prácticas culturales y cosmovisionales que se producen y reproducen con nuevas expresiones en cada momento.

${ }^{14}$ Una expresión, a modo de principio de lo afirmado, puede verse en el Preámbulo de la Declaración cuando dice: «Reconociendo y reafirmando que las personas indígenas tienen derecho sin discriminación a todos los derechos humanos reconocidos en el derecho internacional, y que los pueblos indígenas poseen derechos colectivos que son indispensables para su existencia, bienestar y desarrollo integral como pueblos...». 


\section{b) El vínculo del Derecho indígena con el derecho a la autonomía}

Se trata de poner en conexión los artículos 34 y 35, con el artículo 4, en donde se reconoce «el derecho a la autonomía o autogobierno en las cuestiones relacionadas con los asuntos internos y locales». Se trata de una nueva triagularidad a partir de las exigencias que reclaman para su arraigue los SNI: en este supuesto, de manera evidente, el derecho a la autonomía funciona como condición de posibilidad para el ejercicio de la institucionalidad propia y de la jurisdicción indígena. Elementos inescindibles de las autonomías indígenas serían la territorialidad; la gestión, administración y propiedad de los recursos naturales; el fortalecimiento de la institucionalidad indígena para poder hacerla viable; la profundización política en la delimitación descentralizada de sistemas educativos y de salud propios; el fortalecimiento y sistematización de las distintas formas y prácticas con las que se presenta el Derecho indígena, etc. Ello afecta al corazón de lo que venimos considerando SNI.

En concreto, del espíritu de la Constitución boliviana se deriva la necesidad de combinar un concepto intercultural de jurisdicción indígena, junto con el de territorialidad y autonomía, accediendo, de esta manera, a una rica combinación de principios y derechos constitucionales, en clave intercultural. Es decir, combinar necesariamente estos derechos-fuertes, tan propios de la cosmovisión indígena, más que proceder a una interpretación aislada y atomizada de sus contenidos y naturaleza. Ello otorga importantes pistas para entender las profundidades y exigencias del PJ. Estamos ante la necesaria reciprocidad e interconexión entre derechos individuales y colectivos para poder entender los derechos indígenas en su completud ${ }^{15}$.

Combinar sincrónicamente territorialidad-jurisdicción-autonomía, resulta útil para poder comprender la complejidad de los derechos indígenas, por un lado, y de los SIN, por el otro. La territorialidad permite inferir el ámbito desde el que se definen y delimitan simbólica y materialmente las jurisdicciones

15 Ese es precisamente el tenor y el espíritu del artículo 1 de la Declaración de Naciones Unidas sobre los derechos de los pueblos indígenas cuando establece: «Los indígenas tienen derecho, como pueblos o como personas, al disfrute pleno de todos los derechos bumanos y las libertades fundamentales reconocidos por la Carta de las Naciones Unidas, la Declaración Universal de Derechos Humanos y la normativa internacional de los derechos humanos». Como vemos, insiste en el «disfrute pleno de todos los derechos humanos y libertades fundamentales», en un marco más plural de jurisdicciones. Este artículo habría que dialectizarlo y conjugarlo con el artículo 3 cuando dice: «Los pueblos indígenas tienen derecho a la libre determinación. En virtud de ese derecho determinan libremente su condición política y persiguen libremente su desarrollo económico, social y cultural». 
indígenas. La autonomía indígena permite aproximarse a la delimitación de las competencias reales y concretas que competen a esas jurisdicciones - como ámbito más amplio para enmarcar las relaciones socio-jurídicas de estos pueblos- a partir de una combinación cruzada de intereses y niveles — nacional, departamental, municipal — en la gestión de competencias; y de diferentes ritmos y cosmovisiones en los procesos de construcción e implementación de la(s) autonomía(s) indígena(s) y los procesos de descentralización. La jurisdicción indígena constituye el lugar desde donde fijar procedimientos para que territorialidad y autonomía puedan ejercer sus competencias, y como espacio para la construcción de mecanismos interculturales para la resolución de conflictos entre sistemas jurídicos diferentes, entre interlegalidades distintas: la estatal y la indígena ${ }^{16}$.

\section{c) La coordinación entre jurisdicciones indígena-estatal}

Asentado lo anterior, una parte importante del conflicto entre sistemas normativos tiene que ver con las condiciones de posibilidad y participación en las formas de coordinación. Como se dijo en la primera parte del trabajo, lo que caracteriza al PJ son precisamente principios como coordinación, compenetración y complementariedad. Las condiciones procesales en las que se construye, diseña e implementa la coordinación es fundamental para el sostenimiento de los SNI. Fallas en la dimensión procesal de esta coordinación implican la suspensión del contenido sustantivo de los derechos en juego en este conflicto. La regulación jurídica de este proceso de coordinación puede encontrarse en el Convenio 169 de la OIT, en su artículo 8.2: "procedimientos para solucionar conflictos que puedan surgir». El proyecto de Declaración Americana es más profuso y pertinaz al establecer en su artículo XVI (1) que el derecho indígena deberá ser reconocido como parte del orden jurídico de los Estados, en consulta y con el consentimiento de los pueblos indígenas (XVII (1)). Ello implica, necesariamente, la introducción y adaptación bilateral de los SNI al Estado, pero también, de este último, a los propios pueblos indígenas. Sin una relación dialógica de derechosdeberes, la lógica de los derechos no podría encontrar sustento.

Desde una perspectiva constitucional, en lo que hace referencia a PJ interno, las constituciones de Colombia y Perú reconocen a los pueblos indígenas: i) la potestad de establecer sus propias instituciones y autoridades (autoridades

${ }^{16}$ MARTÍNEZ DE BRINGAS, A., «El reto de hacer efectivo los derechos de los pueblos indígenas: la difícil construcción de una política intercultural», en Pueblos indígenas y política en América Latina, MARTÍ S. (ed.), Barcelona, CIDOB, 2007, págs. 311-340. 
propias, legítimas, naturales); ii) la potestad normativa de darse sus propias normas y procedimientos; iii) la potestad de administrar justicia o ejercer funciones jurisdiccionales, lo que supone la posibilidad de establecer jurisdicciones especiales indígenas, ejercer funciones judiciales específicas para la resolución de conflictos o disponer de instancias de justicia propias.

En cuanto al ámbito de competencias jurisdiccionales ${ }^{17}$, las distintas constituciones manejan registros diferentes en relación a tres esferas de competencias: territorial, personal y material. Colombia y Perú se mueven más en el ámbito de la competencia territorial, a partir de sendos reconocimientos territoriales en la esfera constitucional. Venezuela maneja registros de competencia personal. Ecuador y Bolivia se abren, sin duda, a una consideración material de las jurisdicciones, con amplia competencia personal en el supuesto que los conflictos afectasen a bienes jurídicos indígenas ${ }^{18}$. Sin embargo, en ciertos países, el ámbito material de las jurisdicciones ha sido recortado por vía legislativa, como ha sido el caso de Venezuela a través de la Ley Orgánica de Pueblos Indígenas, o por vía jurisprudencial, como en Colombia. En Colombia, por ejemplo, puede hablarse de jurisdicción ordinaria y jurisdicción especial indígena, teniendo ésta un carácter excepcional y subsidiaria respecto a la vía ordinaria. También aquí, por vía jurisprudencial, se fijaron una serie de límites materiales para evitar desfondar y dejar sin competencia material a la jurisdicción indígena. Esos límites implicaban que la jurisdicción indígena no pudiera afectar ni referir a supuestos que tuviesen que ver con dimensiones que afecten a la vida de las personas, como la pena de muerte; a tortura o esclavitud; o incluso que las decisiones que afectaran a la jurisdicción indígena fueran predecibles, respetando, el sentido procesal del debido proceso ${ }^{19}$.

Los dos últimos procesos constituyentes en América Latina, el boliviano y el ecuatoriano, también han supuesto un ajuste cualitativo, una profundización en los contenidos de un PJ que pueda dar cabida a los SNI. Constituciones como la

17 Cf. IRIGOYEN, R., «El horizonte del constitucionalismo pluralista: del multiculturalismo a la descolonización», en RODRÍGUEZ GARAVITO, C., El Derecho en América Latina. Un mapa para el pensamiento jurídico del siglo XXI, Argentina, 2011, pp. 139-159; «Pluralismo jurídico, derecho indígena y jurisdicción especial en los países andinos» en El Otro Derecho, no 30 , junio 2004, IlSA, Bogotá, pp. 171-195; «Vislumbrando un horizonte pluralista: rupturas y retos epistemológicos y políticos» en CASTRO, M., Los desafíos de la interculturalidad, Universidad de Chile, Santiago de Chile, 2004, pp. 191-228.

18 APARICIO WILHEMI, M. «Sin garantías no hay derechos. Sin derechos no hay Constitución. Apuntes sobre la protección jurisdiccional de los derechos en Ecuador, en Revista de Derecho Político, no 82, 2011, pp. 583-608.

19 SÁNCHEZ JARAMILLO, E., La jurisdicción especial indígena, Procuraduría General de la Nación y Procuraduría Delegada para minorías Étnicas, Bogotá, 2001. 
boliviana no sólo otorga una dimensión específica al tratamiento del SNI, sino que éstos, de alguna manera, resultan trasversales a todo el texto. De hecho, el ejercicio de los sistemas jurídicos indígenas se realizan en consonancia con la cosmovisión de estos pueblos, acercándose, al sentido de PJ esbozado en la primera parte de este artículo.

De manera general, en ambas constituciones se reconoce el principio de PJ, junto con la libre determinación de los pueblos. Ello implica un reconocimiento de las autonomías indígenas como condición para el ejercicio de las jurisdicciones, lo que supone la elección de autoridades de acuerdo a mecanismos de elección propios. En consonancia con esto último, se garantiza la equidad de las mujeres en la participación y formas de representación en sus propios sistemas de autoridad. Además, se establece el principio de igual jerarquía entre jurisdicción indígena y la ordinaria, lo que significa que la jurisdicción indígena originario campesina, en Bolivia, sea autosuficiente y se agote en sí misma, sin necesidad de autorización o validación por parte de la jurisdicción del Estado. Se establece, como novedad, un Tribunal Constitucional Plurinacional de composición plural y paritaria. Se encuadra el PJ en el marco de principios como justicia, solidaridad y diversidad. Se reconocen funciones jurisdiccionales a las autoridades indígenas de acuerdo con el propio derecho.

Pese a todos estos avances reales, en Bolivia se ha procedido a una fuerte limitación de las competencias jurisdiccionales indígenas, densamente reconocidas en la Constitución, por vía legislativa. En este sentido se ha recortado la autonomía indígena como condición de posibilidad más apta para el ejercicio de los SNI; a la vez que se han producido serias limitaciones para el ejercicio de la competencia territorial, material y personal en el ámbito de la jurisdicción indígena.

En lo que hace referencia a la coordinación y resolución de conflictos entre jurisdicciones, en las constituciones de Perú y Colombia se introduce el instrumento de Ley de Coordinación; en Ecuador, de Ley de Compatibilización, mientras que la Constitución boliviana remite a una ley de deslinde jurisdiccional. Resulta fundamental para este ejercicio de coordinación la horizontalidad como criterio regulador y estabilizador del sistema normativo estatal con el indígena. Es esta horizontalidad la que se ha mostrado al final más retórica, y las pretensiones de profundización en el PJ han quedado desbaratadas en los procesos posconstitucionales por vía legislativa, atentando, de esta manera, contra la horizontalidad necesaria reclamada desde el principio de coordinación jurisdiccional. Retazos de estos zarpazos al PJ puede verse en el hecho de que la composición paritaria y la naturaleza netamente intercultural, diseñada para Tribunal Constitucional boliviano, han quedado muy rebajadas por medio de 
regulaciones administrativas posteriores, en el intento de ajustar los SNI al Estado, desnaturalizando aquellos, a la vez que se fortalecía la jurisdicción del Estado en este ejercicio de falsa coordinación inter-jurisdicciones.

\section{d) Justicia indígena y derechos bumanos}

El artículo 34 establece el necesario ajuste del derecho y la justicia indígena a las normas internacionales de derechos humanos. De nuevo este artículo 34 conecta interpretativamente con el artículo 1 de Declaración al decir: «Los indígenas tienen derecho, como pueblos o como personas, al disfrute pleno de todos los derechos humanos y las libertades fundamentales reconocidos por la Carta de las Naciones Unidas, la Declaración Universal de Derechos Humanos y la normativa internacional de los derechos humanos». La conexión a este criterio no funciona como una restricción a la jurisdicción indígena, sino más bien como un criterio de garantismo intercultural. Se expresa como hermenéutica para la comprensión de la totalidad de los SNI en relación con los derechos humanos. Se establece aquí, como criterio intercultural, la necesidad de tensionar todos los derechos colectivos con la dimensión individual de los derechos que corresponden, también, a toda persona indígena. No hay una prioridad lógica, analítica ni epistémica de lo individual sobre lo colectivo, ni de lo colectivo sobre lo individual; sino una constante tensión y confrontación de lo uno con lo otro para resolver conflictos de bienes jurídicos entre derechos. Hay una reconocimiento de la doble dimensión, individual y colectiva, que corresponde en todo momento a los pueblos indígenas, tensión cuya resolución exigiría un análisis intercultural localizado y situado.

Esta tensión es paralela, en los fondos del conflicto, a la necesidad de coordinación entre SNI y sistemas normativos estatales: la tensión en toda su expresión entre cosmovisiones colectivas (indígenas) e individuales (el Estado). Ahora bien, esta dialéctica confrontación, no implica, en ningún momento, un sometimiento de los SNI al derecho interno de los Estados. Los principios de coordinación y autonomía son fundamentales en la lógica de este conflicto para diferenciar al PJ de cualquier expresión de monismo jurídico con pretensiones de pluralidad.

El PNUD también define e identifica el acceso a la justicia indígena con derechos humanos. Lo define como: «La capacidad de los individuos de buscar y obtener una respuesta satisfactoria a sus necesidades jurídicas a través de las instituciones formales o informales de justicia, de conformidad con las normas 
de derechos humanos» ${ }^{20}$. Esta definición, desde la abstracción de atributos culturales, cosmovisionales y colectivos, constituye una consideración de la Justicia en clave de derechos, enrocando, de alguna manera, los SNI en necesidades, pretensiones o expectativas que pueda tener cualquier persona y/o grupo; en cualidades universalizables y predicables respecto de cualquier ser humano. Desde ahí, el propio PNUD desgrana algunos elementos esenciales para dar corporalidad expresa a esta necesidad universal de justica, como son: la protección legal, lo que implicaría reconocimiento de derechos en el interior de los SNI: autonomía, jurisdicción, territorialidad, autoridades e institucionalidad propia, mecanismos y reglas propias de articulación jurisdiccional de acuerdo a criterios culturales y cosmovisionales, etc.; conciencia legal, que implica conocimiento veraz e informado sobre sus propios derechos y, fundamentalmente, sobre el derecho a los SNI; asistencia y asesoramiento legal, lo que implicaría toda la dimensión positiva y capacitadora en el ejercicio de los sistemas de justicia indígena; adjudicación, lo que implica todo el complejo y entramado proceso de articulación inter e intra jurisdicciones; ejecución, esto es, condiciones necesarias para la implementación veraz de los SNI; mecanismos de supervisión por parte de órganos interculturales en el marco de la sociedad civil, etc.

\section{e) Derecho indígena y su conexión con tierras, territorios y recursos naturales}

El derecho indígena, de manera más amplificada, los SNI, alcanzan su máximo expresión, o un nivel de expansión e intensidad muy importante, por medio de su conexión con el derecho a la tierra, al territorio y a los recursos naturales. Ese es el propósito del artículo 26 de la Declaración cuando establece a través de sus tres parágrafos lo siguiente:

1. Los pueblos indígenas tienen derecho a las tierras, territorios y recursos que tradicionalmente han poseído, ocupado o de otra forma utilizado o adquirido.

2. Los pueblos indígenas tienen derecho a poseer, utilizar, desarrollar y controlar las tierras, territorios y recursos que poseen en razón de la propiedad tradicional u otra forma tradicional de ocupación o utilización, así como aquellos que hayan adquirido de otra forma.

3. Los Estados asegurarán el reconocimiento y protección jurídicos de esas tierras, territorios y recursos. Dicho reconocimiento respetará debidamente las costumbres, las tradiciones y los sistemas de tenencia de la tierra de los pueblos indígenas de que se trate.

${ }^{20}$ UNDP, Programming for Justice - Acces for all. A practitioner's Guide to a Human Rights-Based Approach to Access to Justice, 2005. 
La cursiva, nuestra, expresa esa dimensión de los derechos de territorialidad que engarza, complementa, compenetra y da sentido a los SNI. Su fundamento y desarrollo implica y compromete estructuralmente a otros derechos, como los de territorialidad y a los recursos naturales aquí contenidos.

En este mismo sentido hay que interpretar el vínculo del artículo 34 con el 27 de la Declaración. Es el derecho indígena el que es condición de posibilidad de los derechos de propiedad, posesión, y uso de territorios y recursos. Por tanto, formará parte de la articulación de los SNI la forma tradicional de ocupación o utilización de las tierras y territorios, entendiendo que lo tradicional establece el vínculo y conexión entre pueblos indígenas y sus territorios, vínculo al que se debe otorgar plenos efectos jurídicos precisamente por su enroque y arraigue en los SNI. La territorialidad no es un elemento instrumental a los SNI. La territorialidad otorga pertenencia de los pueblos a los lugares que ocupan y utilizan de manera tradicional, precisamente, porque las maneras de habitar, utilizar, usar o usufructuar territorio reside y arraiga en sus SNI. El nivel de relación entre SNI, territorios y recursos es de necesaria complementariedad; no de autónoma funcionalidad.

La Corte Interamericana de Derechos Humanos, por medio de la sentencia de Awas Tingni, hace explícita referencia a esta cuestión al establecer como principio el hecho de que la propiedad comunal indígena sobre tierras tradicionales es producto de la costumbre y del derecho consuetudinario indígena. Por tanto, el reconocimiento de la territorialidad indígena no está vinculado a la existencia de un título oficial de propiedad sobre ellas, ya que son otras expresiones, fundamentadas desde los SNI, las que dan carta de naturaleza y sustento a la territorialidad indígena ${ }^{21}$. Ello es aplicable a los conflictos de propiedad con terceros presentes en territorio indígena, o incluso a la explotación de recursos naturales en territorio indígena ${ }^{22}$.

En este sentido es muy sintomático que la Declaración establezca la necesidad de que el Estado otorgue su «reconocimiento oficial» a través de los procesos de demarcación y titulación. Reconocer no es crear. Los derechos territoriales indígenas existen con carácter pre-estatal; su fundamento y sentido no arraiga, en el orden de su existencia, en el reconocimiento estatal; sí, sin embargo, para su implementación y garantía, que es otra cosa diferente. Por ello, la delimitación, demarcación y titulación debe basarse, también, en el derecho y prácticas

${ }^{21}$ CORTE IDH. Caso de la Comunidad Mayagna (Sumo) Awas Tingni Vs. Nicaragua. Fondo, Reparaciones y Costas. Sentencia de 31 de agosto de 2001. Serie C No. 79, párr. 151.

${ }^{22}$ CORTE IDH. Caso de la Comunidad Mayagna (Sumo) Awas Tingni Vs. Nicaragua. Fondo, Reparaciones y Costas. Sentencia de 31 de agosto de 2001. Serie C No. 79, párr. 153 y ss. 
de estos pueblos, esto es, en sus SNI; no en criterios agraristas, civilistas o estatales en la manera de entender y proyectar la propiedad.

En relación a las violaciones del derecho territorial indígena, el Sistema Interamericano de derechos humanos ha ido haciendo aportaciones sustantivas y de enorme trascendencia para entender las formas y maneras de reparación en estos supuestos, lo que afecta de manera directa y trasversal a la relación de interdependencia que se produce entre los SNI, los derechos territoriales indígenas y el Estado. Se establece en forma de preámbulo de intenciones que la forma más acertada para la reparación es la restitución del territorio ancestral reclamado. Restitutio in integrum lo llama la Corte Interamericana ${ }^{23}$ por considerar que los Estados están obligados a respetar y restituir los derechos a la propiedad comunitaria, así como al otorgamiento gratuito de tierras en extensión y calidad suficientes para la conservación y desarrollo de sus formas de vida ${ }^{24}$, lo que engarza, directamente, con la necesidad de promocionar y proteger los SNI como condición de posibilidad para el ejercicio de los derechos territoriales.

Si no fuera posible la restitución, se impone la necesidad de la compensación de acuerdo con el valor que la tierra perdida tiene para los pueblos indígenas ${ }^{25}$. Esto es, otorgar tierras alternativas en calidad y extensión suficiente, vinculando la calidad, directamente, con el sentido práctico de su uso, ocupación y utilización, a partir de los SNI. Siempre subyace el derecho a la indemnización en estos supuestos de restitución, pero ésta es instrumental y funcional a la restitución del territorio desde las lógicas que los SNI establezcan.

El Comité para la Eliminación de la Discriminación Racial, en su Recomendación General $23^{26}$, ha establecido para los Estados: «que reconozcan y protejan los derechos de los pueblos indígenas a poseer, explotar, controlar y utilizar sus tierras, territorios y recursos comunales, y en los casos en que se les ha privado de sus tierras y territorios, de los que tradicionalmente eran dueños, o se han ocupado o utilizado esas tierras y territorios sin el consentimiento libre e informado de esos pueblos, que adopten medidas para que les sean devueltos. Única-

23 CORTE IDH. Caso de la Comunidad Indígena Xákmok Kásek vs. Paraguay. Fondo, Reparaciones y Costas. Sentencia de 24 de agosto de 2010, Serie C No. 214, párr. 281.

${ }^{24} \mathrm{CIDH}$, Tercer Informe sobre la Situación de los Derechos Humanos en Paraguay. Doc. OEA/ Ser./L/VII.110, Doc. 52, 9 de marzo de 2001, párrs. 50, Recomendación 1.

25 CIDH, Acceso a la Justicia e Inclusión Social: El camino hacia el fortalecimiento de la Democracia en Bolivia. Doc. OEA/Ser.L/V/II, Doc. 34, 28 de junio de 2007, párr. 241. Ver también: CORTE IDH. Caso Comunidad Indígena Yakye Axa Vs. Paraguay. Fondo, Reparaciones y Costas. Sentencia de 17 de junio de 2005. Serie C No. 125, párr. 149.

26 Comité para la Eliminación de la Discriminación Racial - Recomendación general $\mathrm{N}^{\circ} 23$, relativa a los derechos de los pueblos indígenas, $51^{\circ}$ período de sesiones, U.N. Doc. HRI/GEN/1/ Rev.7 at 248 (1997), párr. 5. 
mente cuando, por razones concretas, ello no sea posible, se sustituirá el derecho a la restitución por el derecho a una justa y pronta indemnización, la cual, en la medida de lo posible, deberá ser en forma de tierras y territorios».

Además, la Corte Interamericana ha establecido que las reparaciones por violaciones de derechos territoriales tienen una dimensión individual y otra colectiva ${ }^{27}$, siendo esta última la que nos interesa por su conexión con los SNI. En este sentido establece que las reparaciones han de cubrir los daños inmateriales causados a los pueblos por la violación de sus derechos territoriales, entendiendo por daño inmaterial el «[que] puede comprender tanto los sufrimientos y las aflicciones causados a las víctimas directas y a sus allegados, el menoscabo de valores muy significativos para las personas, así como las alteraciones, de carácter no pecuniario, en las condiciones de existencia de la víctima o su familia» ${ }^{28}$. Para la valoración de los daños inmateriales ha de tenerse especialmente en cuenta que la falta de garantía del derecho a la propiedad comunitaria causa sufrimiento a los miembros de las comunidades indígenas afectadas ${ }^{29}$; así como la falta de concreción del derecho a la propiedad comunal, o las graves condiciones de vida a las que se han visto expuestos los miembros de la comunidad correspondiente como consecuencia de la demora estatal en la realización efectiva de sus derechos territoriales ${ }^{30}$.

La especial relación entre los pueblos indígenas y tribales y sus territorios tradicionales, también ha sido tenida en cuenta por la Corte a la hora de establecer las reparaciones Así, en el caso Moiwana, la Corte consideró que el desplazamiento forzoso de la comunidad había causado daños emocionales, espirituales, culturales y económicos a sus miembros, considerando este hecho relevante para el cálculo de las reparaciones por daño inmaterial que el Estado debía otorgar ${ }^{31}$. En efecto, la relación con el territorio y su significado es relevante para fijar el monto de las indemnizaciones compensatorias: «la significación especial que la tierra tiene para los pueblos indígenas en general (...) implica que toda denegación al goce o ejercicio de los derechos territoriales acarrea el menoscabo

27 CORTE IDH. Caso Comunidad Indígena Yakye Axa Vs. Paraguay. Fondo, Reparaciones y Costas. Sentencia de 17 de junio de 2005. Serie C No. 125, párrs. 188 y 189.

28 CORTE IDH. Caso Comunidad Indígena Sawhoyamaxa Vs. Paraguay. Fondo, Reparaciones y Costas. Sentencia de 29 de marzo de 2006. Serie C No. 146, párr. 219.

29 CORTE IDH. Caso Comunidad Indígena Sawboyamaxa Vs. Paraguay. Fondo, Reparaciones y Costas. Sentencia de 29 de marzo de 2006. Serie C No. 146, párrs. 73-75.

30 CORTE IDH. Caso Comunidad Indígena Yakye Axa Vs. Paraguay. Fondo, Reparaciones y Costas. Sentencia de 17 de junio de 2005. Serie C No. 125, párr. 202.

31 CORTE IDH, Caso Comunidad Moiwana vs. Surinam. (Excepciones Preliminares, Fondo, Reparaciones y Costas). Sentencia de 15 de junio de 2005, Serie C No. 124, párr. 195(c). 
de valores muy representativos para los miembros de dichos pueblos, quienes corren el peligro de perder o sufrir daños irreparables en su vida e identidad cultural y en el patrimonio cultural a transmitirse a futuras generaciones» ${ }^{32}$. Para los pueblos indígenas y tribales, «la posesión de su territorio tradicional está marcada de forma indeleble en su memoria histórica y la relación que mantienen con la tierra es de una calidad tal que su desvinculación de la misma implica riesgo cierto de una pérdida étnica y cultural irreparable, con la consecuente vacante para la diversidad que tal hecho acarrearía ${ }^{33}$. En forma similar, en el caso de la comunidad Sawhoyamaxa, la Corte Interamericana tuvo en cuenta, al valorar el daño inmaterial, «la falta de concreción del derecho a la propiedad comunal de los miembros de la comunidad Sawhoyamaxa, así como las graves condiciones de vida a las que se han visto sometidos como consecuencia de la demora estatal en la efectivización de sus derechos territoriales $»^{34}$. Como ha quedado evidenciado, existe todo el rato una relación estructural, complementaria e interdependiente entre SNI y territorialidad indígena en un sentido lato.

También es importante hacer referencia a las reparaciones en aquellos supuestos que afecten a recursos naturales sitos en territorio ancestral, por las implicativas referencias que éstas tienen para los SNI. Puede hablarse de indemnizaciones por daños ambientales causados por proyectos de exploración y explotación de recursos en la medida que afecten a las actividades básicas de subsistencia de los pueblos indígenas, prácticas enclavadas estructuralmente en lo que venimos llamando $\mathrm{SNI}^{35}$.

El artículo 40 de la Declaración también es muy denotativo a este respecto cuando habla de «una reparación efectiva de toda lesión de sus derechos individuales y colectivos». Con ello se está aludiendo a daños causados sobre la capacidad productiva de las tierras, sobre sus recursos, o que afecten a la propia salud de los pueblos indígenas, elementos, todos ellos, que conectan con cuestiones axiológicas culturalmente arraigadas en las cosmovisiones y en los SNI. No se acota el tenor de estas disposiciones sólo para los Estados,

32 CORTE IDH. Caso Comunidad Indígena Yakye Axa Vs. Paraguay. Fondo, Reparaciones y Costas. Sentencia de 17 de junio de 2005. Serie C No. 125, párr. 203.

33 CORTE IDH. Caso Comunidad Indígena Yakye Axa Vs. Paraguay. Fondo, Reparaciones y Costas. Sentencia de 17 de junio de 2005. Serie C No. 125, párr. 216.

${ }^{34}$ CORTE IDH. Caso Comunidad Indígena Sawhoyamaxa Vs. Paraguay. Fondo, Reparaciones y Costas. Sentencia de 29 de marzo de 2006. Serie C No. 146, párr. 221.

35 CIDH, Democracia y Derechos Humanos en Venezuela. Doc. OEA/Ser.L/V/II, Doc. 54, 30 de diciembre de 2009, párr. 1137, Recomendación 6. Ver también: CIDH, Acceso a la Justicia e Inclusión Social: El camino hacia el fortalecimiento de la Democracia en Bolivia. Doc. OEA/Ser.L/V/II, Doc. 34, 28 de junio de 2007, párr. 297, Recomendación 6. 
sino que también refieren y afectan a empresas comerciales y otros actores privados. Cuando se habla, en relación a estas reparaciones, de mecanismos efectivos y accesibles de reparación, efectividad y accesibilidad son adjetivaciones que deben cobrar sentido desde el marco de los SNI, esto es, desde otras calificaciones normativas que las del Estado. El derecho a participar en la determinación de los daños ambientales causados por estos proyectos implica tener en cuenta de manera directa y estructural lo que se consideran como actividades básicas de subsistencia para estos pueblos, incluyendo sus propias prioridades de desarrollo, e implicando de manera estructural ese gran paraguas normativo que son los $\mathrm{SNI}^{36}$.

La sentencia sobre el caso Saramaka establecía de manera contundente que: «(...) el daño ambiental y la destrucción de las tierras y recursos utilizados tradicionalmente por el pueblo Saramaka, así como el impacto que ello tuvo sobre la propiedad de dicho pueblo, no sólo en cuanto a los recursos de subsistencia sino también respecto de la conexión espiritual que el pueblo Saramaka tiene con su territorio (...). Asimismo, existe prueba que indica el sufrimiento y la angustia que el pueblo Saramaka ha atravesado como resultado de una larga y continua lucha por el reconocimiento legal de su derecho al territorio que tradicionalmente han ocupado y utilizado durante siglos (...), así como la frustración respecto del sistema legal interno que no los protege contra violaciones a dicho derecho (...). Todo ello constituye una denigración de sus valores culturales y espirituales. La Corte considera que el daño inmaterial que estas alteraciones causaron en el tejido de la sociedad misma del pueblo Saramaka les da el derecho de obtener una justa indemnización» ${ }^{37}$. Además la Corte añadió que: «todos los asuntos relacionados al proceso de consulta con el pueblo Saramaka, así como aquellos relacionados a los beneficiarios de la "justa indemnización” que se debe compartir, deberán ser determinados y resueltos por el pueblo Saramaka de conformidad con sus costumbres y normas tradicionales, y según lo ordenado por el Tribunal en la Sentencia» ${ }^{38}$.

36 CIDH, Democracia y Derechos Humanos en Venezuela. Doc. OEA/Ser.L/V/II, Doc. 54, 30 de diciembre de 2009, párr. 1137, Recomendación 6. Ver también: CIDH, Acceso a la Justicia e Inclusión Social: El camino hacia el fortalecimiento de la Democracia en Bolivia. Doc. OEA/Ser.L/V/II, Doc. 34, 28 de junio de 2007, párr. 297, Recomendación 6.

37 CORTE IDH. Caso del Pueblo Saramaka Vs. Surinam. Excepciones Preliminares, Fondo, Reparaciones y Costas. Sentencia de 28 de noviembre de 2007. Serie C No. 172, párr. 200.

${ }^{38}$ CORTE IDH. Caso del Pueblo Saramaka Vs. Surinam. Interpretación de la Sentencia de Excepciones Preliminares, Fondo, Reparaciones y Costas. Sentencia de 12 de agosto de 2008: Serie C No. 185, párr. 27. 


\section{ESPECIFICACIONES Y COMPLEMENTOS A LOS SNI DESDE EL PLURALISMO JURÍDICO}

Transitaremos en este epígrafe a través de dos momentos que guardan conexión entre sí. En primer lugar, complementando los contenidos materiales de los SNI — cuya conexión con principios y derechos colectivos en la Declaración han quedado ya establecidos en el epígrafe III de este trabajo- por medio de otros contenidos y aportes sustraídos de informes y pronunciamientos de la Comisión Interamericana de Derechos Humanos y sentencias de la Corte, en el marco de la OEA, con el fin de otorgar un fundamento más sólido y desarrollado a los SNI. Se trata, en definitiva, de proponer más argumentos que permitan fundamentar el derecho a los SNI, centrando la atención en los mecanismos administrativos efectivos para el acceso a la justicia, de cara a proteger, garantizar y promover los derechos territoriales indígenas. Procederemos, también, en un segundo momento, exponiendo otras experiencias que refuercen los SNI, no ya en el marco de la OEA, sino desde el ámbito jurídico internacional de otros pueblos indígenas.

Cuando se habla de mecanismos administrativos efectivos para el acceso a la justica ¿a qué estamos aludiendo? ¿qué tipo de referencias jurídicas interculturales implican éstos para los pueblos indígenas y para los Estados? ¿nos movemos en el ámbito de lo factible, o en el de la ficción jurídica? La Corte Interamericana, en íntima conexión con el artículo 25 de la Convención Americana de Derechos Humanos, ha establecido que fijar mecanismos efectivos para cuestiones como la titulación o la demarcación territorial implica atender a las «características particulares» de estos pueblos, lo que exige una exploración sobre los fondos normativos de los $\mathrm{SNI}^{39}$. Corresponderá a los Estados fijar estos procedimientos garantizando siempre que su tramitación sea accesible y simple, y que los órganos a su cargo cuenten con las condiciones técnicas y materiales necesarias para dar oportuna respuesta a las solicitudes que se les hagan en el marco de dichos procedimientos ${ }^{40}$. Para ello debe evitarse todo tipo de medidas regresivas, aquellas donde la dimensión procesal y procedimental del derecho estatal pueda arruinar y vaciar de contenido los derechos indígenas.

En materia de acceso a la justicia se entiende por derecho a un recurso administrativo la posibilidad de obtener una solución definitiva, en relación a la cuestión

39 CORTE IDH. Caso de la Comunidad Mayagna (Sumo) Awas Tingni Vs. Nicaragua. Fondo, Reparaciones y Costas. Sentencia de 31 de agosto de 2001. Serie C No. 79, párrs. 122 y 123.

40 CORTE IDH. Caso Comunidad Indígena Yakye Axa Vs. Paraguay. Fondo, Reparaciones y Costas. Sentencia de 17 de junio de 2005. Serie C No. 125, párr. 102. 
territorial planteada, en un plazo razonable y sin demoras injustificadas. Tasar como vulneración de derechos la ineficacia administrativa del Estado, en los supuestos de reclamación territorial, es muy importante, puesto que, aunque son expresiones de libertad negativa ${ }^{41}$, su conculcación implica la suspensión, desplazamiento y vaciamiento de contenidos materiales de los SNI, en la manera de entender los derechos territoriales. Ello implica, a su vez, la vulneración de los mecanismos de elección y representación propios de los pueblos indígenas; de las dinámicas autóctonas de adjetivación de la personalidad jurídica de comunidades afectadas por conflictos, expresión de representación jurídica colectiva de estos pueblos; o el desplazamiento de procedimientos ad hoc para la titulación, demarcación y restitución de tierras, más allá de los clásicos mecanismos administrativos fijados por el Estado y ofertados como terapia alternativa a los conflictos. Las demoras y retrasos en los procesos de identificación de tierras serían, también, trazas claras de la vulneración del goce efectivo a la territorialidad indígena ${ }^{42}$. Demoras prolongadas, como los 11 años del caso Yakye Axa para implementar las disposiciones que establecía la sentencia, constituyen, sin duda, una violación de las garantías judiciales ${ }^{43}$.

Como ha dejado claro el Relator Especial para pueblos indígenas ${ }^{44}$, la estructura institucional de la administración pública es un obstáculo, en sí misma, para la implementación de las disposiciones jurídicas que protegen los derechos de los pueblos indígenas, siendo una manifestación clara de ello, la «brecha de implementación», esto es, el desfase programático entre lo establecido en la ley y la aplicación real y operativa de la misma. La dimensión administrativa del Estado está mal pertrechada para asumir la multiculturalidad y el derecho a la diferencia, las políticas de reconocimiento y la igualdad compleja. Clara expresión de ello serían toda el conjunto de criterios y propuestas asimilacionistas desplegadas por las políticas públicas de los Estados para desarrollar e implementar derechos indígenas. A ello habría que añadir la discriminación estructural instalada como eje de funcionamiento en muchos órganos del Estado,

41 No se trata de promocionar el derecho indígena al propio proceso, si no de reconocer, que la ineficacia estatal en el cumplimiento de sus obligaciones y responsabilidades, en asegurar el acceso a la justica, vulnera las posibilidades de defensa de los pueblos indígenas, en un primer nivel, y por conexión diferida, los derechos sustantivos a la justica indígena.

42 CIDH, Acceso a la Justicia e Inclusión Social: El camino hacia el fortalecimiento de la Democracia en Bolivia. Doc. OEA/Ser.L/V/II, Doc. 34, 28 de junio de 2007, párrs. 235, 238, 244; 297 - Recomendación 3 .

43 CORTE IDH. Caso Comunidad Indígena Yakye Axa Vs. Paraguay. Fondo, Reparaciones y Costas. Sentencia de 17 de junio de 2005. Serie C No. 125, párr. 86.

44 Informe del Relator Especial sobre la situación de los derechos humanos y las libertades fundamentales de los indígenas, Sr. Rodolfo Stavenhagen. Doc. ONU E/CN.4/2006/78, párr. 87. 
en relación a pueblos indígenas; así como el racismo de Estado tan densamente instalado en la trama interna de su práctica política, y un largo etcétera.

Con el fin de ajustar el discurso de derechos a los SNI, y más en concreto, el artículo 25 de la Convención Americana de Derechos Humanos sobre "protección judicial», y el 8 sobre «garantías judiciales», la Corte Interamericana ha establecido la necesidad de que el Estado tenga siempre en cuenta las particularidades propias de los pueblos indígenas, sus características económicas y sociales, y el derecho consuetudinario, junto con valores, usos y costumbres, así como la especial situación de vulnerabilidad en la que se encuentran estos pueblos. Ha apuntillado al respecto que los sistemas normativos estatales deben adaptarse y habilitarse para dar cabida a los procesos y procedimientos propios de estos pueblos en la manera de gestionar y tratar con el territorio. Corresponderá, incluso, al Estado la habilitación y capacitación necesaria de sus funcionarios para dar respuesta al reto de los $\mathrm{SNI}^{45}$. Se hace necesario que los Estados desarrollen una evaluación completa de la situación de las comunidades que vayan a ser objeto de titulación territorial, así como de las dificultades técnicas, jurídicas y administrativas que hayan podido incidir en tal desposesión $^{46}$. La Comisión Interamericana $(\mathrm{CIDH})$ ha establecido que corresponde a los Estados asegurar los fondos y recursos necesarios para dar cumplimiento a las obligaciones constitucionales y a las del derecho internacional de los derechos humanos, poder dar respuesta a los contenidos de los derechos territoriales indígenas ${ }^{47}$.

En materia de tutela judicial efectiva la Corte Interamericana ha establecido que la ausencia de recursos judiciales efectivos supone una violación de los artículos 8, 25, 2 y 1.1 de la Convención Americana. No basta con que existan tales recursos; estos deben ser efectivos, siendo el Estado responsable de la debida aplicación de los mismos por parte de las autoridades judiciales, adoptando

45 CORTE IDH. Caso Comunidad Indígena Yakye Axa Vs. Paraguay. Fondo, Reparaciones y Costas. Sentencia de 17 de junio de 2005. Serie C No. 125, párr. 63. CORTE IDH. Caso Comunidad Indígena Sawhoyamaxa Vs. Paraguay. Fondo, Reparaciones y Costas. Sentencia de 29 de marzo de 2006. Serie C No. 146, párrs. 82 y 83; CORTE IDH. Caso Comunidad Indígena Sawhoyamaxa Vs. Paraguay. Fondo, Reparaciones y Costas. Sentencia de 29 de marzo de 2006. Serie C No. 146, párr. 104 y 108.

$46 \mathrm{CIDH}$, Acceso a la Justicia e Inclusión Social: El camino hacia el fortalecimiento de la Democracia en Bolivia. Doc. OEA/Ser.L/V/II, Doc. 34, 28 de junio de 2007, párr. 229, 275, 276 y 297. Así como la Recomendación 9.

$47 \mathrm{CIDH}$, Tercer Informe sobre la Situación de los Derechos Humanos en Paraguay. Doc. OEA/ Ser./L/VII.110, Doc. 52, 9 de marzo de 2001, párr. 50 - Recomendación 2. Ver también CORTE IDH. Caso Comunidad Indígena Sawhoyamaxa Vs. Paraguay. Fondo, Reparaciones y Costas. Sentencia de 29 de marzo de 2006. Serie C No. 146, párr. 143. 
medidas afirmativas que garanticen que los recursos adoptados y aportados son eficaces $^{48}$. En definitiva, la ausencia de tutela judicial efectiva implica una vulneración del derecho sustantivo a la protección judicial de los pueblos indígenas; y esta violación se produce siempre que el procedimiento diseñado para implementar dicho derecho no tenga en cuenta los SNI. Incluso la revisión judicial de las decisiones administrativas que modifiquen o extingan títulos jurídicos de propiedad de los pueblos indígenas debe estar basada en una evaluación judicial que evidencie la pertinencia de dicha modificación. Esto es, se trata en última instancia de una aplicación del principio pro homine: proceder de tal manera que las medidas que se adopten beneficien siempre a la parte más frágil para cuya protección y salvaguardia se institucionalizan los derechos humanos.

De manera sintética podríamos decir que las decisiones judiciales del Estado que deberán quedar sujetas a revisión judicial serían: i) las relativas a la aprobación del planes o proyectos con incidencia en territorio indígena. Ello incluye todas las cuestiones relativas a la consulta, el resultado de la misma, así como el deber estatal de obtener el consentimiento de los pueblos indígenas, como se desprende del tenor de la Declaración y del Convenio 169 de la OIT; ii) las decisiones relativas a la aprobación de estudios de impacto social y ambiental; o la falta de realización de los mismos, con certificación y aval sobre la calidad, objetividad e independencia de dichos estudios; iii) las decisiones relativas al establecimiento de mecanismos de participación en los beneficios u otras formas de compensación en lo que a explotación de industrias hidrocarburíferas atañe.

Todas estas garantías judiciales tratan de regular y controlar cualquier posible extralimitación del Estado en su manera de entender y aplicar el PJ. Ello es ya una manera de proceder sólidamente arraigada y consolidada en los operadores jurídicos de la OEA.

Existen, además, otros prismas del acceso a la justicia que tienen más que ver con la dimensión colectiva de los derechos de los pueblos indígenas, que con la dimensión individual de los mismos. Una de estas dimensiones sería el reconocimiento de la capacidad jurídica colectiva de los pueblos indígenas, en cuanto titulares del derecho de propiedad comunal, lo que implica el acceso a la justicia

${ }^{48} \mathrm{CIDH}$, Alegatos ante la CORTE Interamericana de Derechos Humanos en el caso de Sawhoyamaxa v. Paraguay. Referidos en: CORTE IDH. Caso Comunidad Indígena Sawhoyamaxa Vs. Paraguay. Fondo, Reparaciones y Costas. Sentencia de 29 de marzo de 2006. Serie C No. 146, párr. 74(b); CORTE IDH. Caso de la Comunidad Mayagna (Sumo) Awas Tingni Vs. Nicaragua. Fondo, Reparaciones y Costas. Sentencia de 31 de agosto de 2001. Serie C No. 79, párr. 135; CIDH, Informe No. 40/04, Caso 12.053, Comunidades Indígenas Mayas del Distrito de Toledo (Belice), 12 de octubre de 2004, párr. 184. CIDH, Informe 11/98, Caso 10.606, Samuel de la Cruz Gómez (Guatemala), párr. 52 y 126. 
como sujeto colectivo — comunidad-y de conformidad con sus SNI. El derecho de los pueblos indígenas al acceso a la justica, en un sentido lato, implica que éstos puedan participar como partes - como sujetos colectivos- en los procesos ante los órganos judiciales ${ }^{49}$. Por tanto, la capacidad de obrar colectiva de estos pueblos forma parte de este derecho, que se deriva y fundamenta en el carácter colectivo del título de propiedad indígena. En el caso Saramaka vs. Surinam la Corte estableció que la limitación de la personalidad jurídica colectiva atenta contra la naturaleza colectiva del derecho a usar y gozar la propiedad de acuerdo a sus tradiciones ancestrales ${ }^{50}$. De nuevo se vuelve a establecer un criterio intercultural, desde la perspectiva de los SNI, en la sensible y delicada dialéctica de confrontación entre derechos individuales y colectivos de los pueblos indígenas.

Son muy claras las palabras de la Corte al establecer que la falta de reconocimiento de la dimensión colectiva de la subjetividad jurídica sitúa a los pueblos afectados en una situación de extrema vulnerabilidad, al producirse una posible primacía e imposición de los derechos individuales sobre los derechos de propiedad comunal, lejos del equilibro dialéctico que este maridaje exige. Ello imposibilita fundamentar la necesidad de protección judicial de estos pueblos como consecuencia de la violación de sus derechos colectivos, tal y como quedan recogidos en el artículo 21 de la Convención Americana ${ }^{51}$. Como ya ha quedado evidenciado, la personalidad jurídica colectiva implica necesariamente el reconocimiento paralelo de las formas de organización política y social propia de estos pueblos.

Como se aventuró al inicio de este epígrafe, ofreceremos algunos ejemplos más de articulación de los SNI — anclados en este esquema reductivo de entender el todo por la parte- orientados a fracturar el sentido colectivo de los derechos y de lo jurídico. Así por ejemplo, en Bangladesh se ha procedido al reconocimiento del derecho consuetudinario familiar. Ello es un ejemplo claro de que el reconocimiento de los sistemas legales indígenas por el Estado depende de la naturaleza de los casos que se presenten. Se manejan, por tanto, criterios selectivos. Las leyes personales de los pueblos indígenas de Chittagong Hill Tracts en

49 CORTE IDH. Caso del Pueblo Saramaka Vs. Surinam. Excepciones Preliminares, Fondo, Reparaciones y Costas. Sentencia de 28 de noviembre de 2007. Serie C No. 172, párr. 194(b); CIDH, Acceso a la Justicia e Inclusión Social: El camino bacia el fortalecimiento de la Democracia en Bolivia. Doc. OEA/Ser.L/V/II, Doc. 34, 28 de junio de 2007, párr. 280.

50 CORTE IDH. Caso del Pueblo Saramaka Vs. Surinam. Excepciones Preliminares, Fondo, Reparaciones y Costas. Sentencia de 28 de noviembre de 2007. Serie C No. 172, párr. 168.

${ }^{51}$ CORTE IDH. Caso del Pueblo Saramaka Vs. Surinam. Excepciones Preliminares, Fondo, Reparaciones y Costas. Sentencia de 28 de noviembre de 2007. Serie C No. 172, párr. 173. 
Bangladesh, que afectan a diferentes cuestiones de orden comunitario-familiar, como puede ser la herencia o el matrimonio, sólo son aceptadas por el Estado en la medida que dicha legislación indígena doméstica no entre en conflicto con el sistema normativo estatal ${ }^{52}$. Ello es un claro ejemplo de tratamiento de los SNI en clave asimilativa y adaptativa al sistema normativo estatal, condición necesaria para reconocer y garantizar el pluralismo.

En Kenia se ha producido un reconocimiento limitado del derecho consuetudinario en el supuesto de los Maasai. Hay muchos elementos que quedan recogidos bajo esta titulación consuetudinaria: matrimonios, adopciones, entierros, regímenes de transmisión de propiedad, e incluso el reconocimiento de autoridades y jefes. Ocurre, sin embargo, que las condiciones de validez del «derecho consuetudinario» de los Maasai queda condicionada y rebajada por lo que se ha venido llamando la «cláusula de contrariedad». Ésta establece que el derecho consuetudinario es válido en la medida que está en consonancia, y, por tanto, no contradiga las leyes escritas. Cláusula muy similar al tratamiento del derecho indígena en muchas constituciones latinoamericanas. La cláusula es utilizada con sistematicidad para recortar los derechos sobre la tierra y los recursos de los Maasai ${ }^{53}$, en una interpretación espuria que quiebra las disposiciones de los derechos indígenas contenidas en el Derecho Internacional de los Derechos humanos.

En Finlandia, Noruega y Suecia, en relación al reconocimiento de las costumbres y el derecho consuetudinario Sámi, se han producido aplicaciones e interpretaciones restrictivas de los derechos indígenas, pese a que las costumbres y prácticas tradicionales Sámi son fuente de aplicación del derecho en los respectivos sistemas jurídicos nacionales. Sería importante, para la implementación de un PJ respetuoso con el contenido de todo lo que hemos venido exponiendo, que las tradiciones jurídicas Sámi tengan capacidad para informar y dar contenido a las fuentes normativas estatales; las complementen y las maticen en aquellos aspectos en que irrumpan conflictos jurídicos entre ambos sistemas normativos ${ }^{54}$.

En Namibia, respecto al reconocimiento de autoridades tradicionales, el Comité para la Eliminación de la Discriminación Racial (CERD) ha cuestionado la falta de criterios específicos y sustantivos, así como la ausencia de instituciones que puedan sustanciar, o evaluar, un procedimiento, como el del reconocimien-

52 ILO, Indigenous and Tribal Peoples Right in Practice. A Guido to ILO Convention N ${ }^{o} .169$, 2009 , p. 87.

${ }_{53}$ Op. cit, p. 88.

${ }^{54}$ Ibidem. 
to de dirigentes tradicionales. La Ley de Autoridades Tradicionales del 2000 preveía el reconocimiento de las mismas, por parte del Estado, siempre que se elevara una solicitud ad hoc al respecto, con lo que la capacidad final para el reconocimiento de autoridades tradicionales reposaba exclusivamente en manos del gobierno. Ni siquiera podemos hablar de una tentativa de pluralismo en este supuesto, sino, más bien, de mera asimilación jurídica de los $\mathrm{SNI}^{55}$.

Sin embargo, en el supuesto de Groenlandia, su Código Penal se basa, en parte, en el derecho consuetudinario de los Inuit, al que se recurre para la sanción de delitos penales, mientras que la determinación de culpabilidad, así como su imputabilidad, viene establecida por el derecho penal danés. Este paisaje normativo, con este reparto material de competencias normativas entre diferentes sistemas, se atiene más a lo que venimos reclamando como verdadero $\mathrm{PJ}^{56}$.

Finalmente, en Filipinas, la Ley de Derechos de los Pueblos Indígenas reconoce el derecho de estos pueblos a emplear sistemas jurídicos, instituciones de resolución de conflictos, procesos y mecanismos para la consolidación de otras leyes y prácticas consuetudinarias, en la medida que sean compatibles con el sistema jurídico nacional y los derechos humanos. Se trata de una expresión muy adelgazada de PJ, a partir de esa exigencia de compatibilidad con el sistema jurídico nacional que determina criterios de validez y legitimidad últimos ${ }^{57}$.

\section{CONCLUSIONES}

Sally Engle Merry sistematizaba las grandes aportaciones del PJ en torno a tres ejes: i) el de la interacción entre órdenes normativos que son fundamentalmente diferentes en sus principios conceptuales y fundamentos de sentido; ii) el de la elaboración del derecho consuetudinario como producto histórico; iii) el de la dialéctica entre órdenes o sistemas normativos diferentes ${ }^{58}$. Si hemos venido defendiendo que los SNI constituyen una plurificación y complejificación del añejo sentido de PJ, es porque éstos unifican e integran de manera interdependiente y solapada estos tres ejes, otorgando una imagen inconsútil y unificada. No es posible discernir en los SNI, de manera autónoma y aislada, cualquiera

55 Observaciones finales del CERD: CERD/C/Nam/CO/12 (Namibia, agosto de 2008).

${ }^{56} \mathrm{ILO}$, Indigenous and Tribal Peoples Right in Practice. A Guido to ILO Convention N ${ }^{\circ}$. 169, 2009 , p. 89.

57 http://www.ncip.gov.ph/mandatedetail.php? $\bmod =i p r a$

58 MERRY, S.E., «Pluralismo Jurídico», en MERRY S.E., GRIFFITHS, J., TAMANAHA, B. Z., Pluralismo Jurídico, Siglo del Hombre Editores, Bogotá, 2007, p. 97. 
de estos ejes, sin descomponer el complejo y articulado sentido que los SNI guardan como totalidad.

Una de las tentaciones o perversiones de un supuesto PJ estatalizado es reducir los SNI a uno sólo de estos ejes, como se ha venido mostrando a lo largo del trabajo. Este ejercicio de exclusión, que hemos intentado explicar, debe ser expurgado para poder articular un verdadero PJ. El nuevo constitucionalismo latinoamericano, las reformas constitucionales que se han venido propiciando, así como los nuevos intentos normativos por auparse al tren de la historia del PJ han acabado tratando los SNI de manera asimilativa, según los usos y costumbres de las vieja política pública. El intento de este ensayo, a partir de las excusas y provocaciones que otorgan los SNI, ha sido el de ubicar el carácter novedosamente cualitativo que éste - y en su conjunto, todos y cada uno de los SNI - tienen y tendrán para renovar el diálogo y los procesos de profundización en el PJ.

En este sentido ha sido enormemente importante establecer la conexión que los SNI mantienen, en una suerte de interdependencia, con otros derechos colectivos indígenas: la territorialidad, la autonomía, la cultura, la jurisdicción indígena, etc. Con ello se quería expresar que los SNI constituyen un nudo cosmovisional de derechos. La formulación de los SNI como derecho propio de estos pueblos es, por tanto, condición de posibilidad para la producción, reproducción y desarrollo de otros derechos indígenas, individuales y colectivos; así como su no consideración implica la vulneración de otros derechos estructuralmente vinculados a los SNI, entre ellos, el derecho al debido proceso.

Title:

THE RIGHT TO THE INDIGENOUS LEGAL SYSTEMS UNDER THE LEGAL PLURALISM. AN ANALYSIS FROM A RIGHT PERSPECTIVE

\section{Resumen:}

Este artículo se estructura en cuatro grandes momentos. Un primer momento, en donde establecer las condiciones para fijar el fundamento de un posible derecho a los que hemos llamado Sistemas Normativos Indígenas (SIN) como referente fundamental para definir el Pluralismo Jurídico. Un segundo momento, en el que situar el concepto de justicia indígena en el discurso de los derechos humanos, teniendo 
en cuenta tanto referencias constitucionales de América Latina (Bolivia, Ecuador, Bolivia) como del Sistema Internacional de derechos humanos. Es aquí en donde pondremos los SNI en conexión con una serie de principios básicos como son: el derecho a la cultura propia; el derecho a la autonomía; la necesaria coordinación entre jurisdicción indígena y estatal; el necesario vínculo de la justicia indígena con los derechos humanos; y el vínculo esencial entre el derecho indígena y sus tierras, territorios y recursos naturales. Un tercer momento en el que se establecen especificaciones y complementos al intento de fundamentar el derecho a los SNI, pero desde los pronunciamientos, informes, sentencias, ajustes jurídicos para entender los derechos de los pueblos indígenas, realizados por otros operadores jurídicos en el marco del espacio regional de protección de los derechos humanos: la OEA, y especialmente, a partir de intervenciones de la Corte y la Comisión Interamericana de derechos humanos, así como de referencias constitucionales latinoamericanas. Estos pronunciamientos e intervenciones funcionan como resortes jurídicos que complementan la construcción de un discurso jurídico de derechos humanos en relación a los pueblos indígenas, y muy especialmente, refuerzan el derecho a los SNI.

\begin{abstract}
:
This article is divide into four great moments. Initially, in which to establish the conditions to set the foundations for a possible right to Indigenous Legal Systems (ILS) as a fundamental reference for defining Legal Pluralism. A second time, placing the concept of indigenous people's justice in the discourse of human rights, taking into account constitutional references in Latin America (Bolivia, Ecuador, Colombia, etc.) and the International System of Human Rights. This is where we will put the ILS in connection with a series of basic principles such as: the right to their own culture; the right to autonomy; the necessary coordination between indigenous jurisdiction and state jurisdiction; the necessary link of indigenous justice with human rights; and the essential bound between ILS and their lands, territories and natural resources. A third stage in establishing specifications and supplements to attempt and ground the right to the ILS, taking into consideration the statements, reports and legal adjustments to understand the rights of indigenous peoples by other legal practitioners under the regional forum for protection the human rights: the Organization of American States. These pronouncements and legal interventions work as springs that complement the construction of a
\end{abstract}


legal discourse of human rights in relation to indigenous peoples and, especially, reinforcing the right to ILS.

Palabras clave:

Pluralismo Jurídico; Sistemas Normativos indígenas; Estado; Constitución; derechos humanos

Key words:

Legal Pluralism; Indigenous Legal System; State; Constitution; Human Rights. 